\title{
Reconstruction of orbital floor fractures using a porous polyethylene implant: outcomes in the early, intermediate and late postoperative periods
}

\author{
Nese Kurt Ozkaya ${ }^{1}$, Ali Rıza Ercöcen² \\ 1 Department of Plastic Reconstructive Aesthetic Surgery, Sivas Cumhuriyet University Faculty of Medicine, Sivas, Turkey. \\ 2 Department of Plastic Reconstructive Aesthetic Surgery, Bayındır HealthCare Group Hospitals, Bayındır Hospital Icerenköy, Istanbul, Turkey.
} Nese Kurt Ozkaya, ORCID: 0000-0002-0817-1854

Ali Riza Ercöcen, ORCID: 0000-0003-4144-3134

\begin{abstract}
Objective: The porous polyethylene implant (PPEI) is one of the most commonly used alloplastic materials in cranio-maxillofacial surgery. It is widely preferred because of its biocompatible, durable, flexible and thin nature as well as for its low complication rates. The purpose of the present study was to review the clinical and surgical outcomes of PPEI usage for orbital floor fractures.
\end{abstract}

Methods: The present study included 76 patients who underwent orbital floor fracture reconstruction using PPEI between July 2000 and July 2018. All demographic characteristics of the patients were recorded and the patients were questioned and/or examined whether there was any complaint or complication secondary to the surgery.

Results: The mean age of the patients was 35.2 years with a male predominance. The most common causes of injury were in-vehicle traffic accidents, falls, physical assaults and pedestrian accidents, respectively. 73 patients had other concomitant fractures of the facial bones along with the orbital floor fracture. The mean time between the injury and the surgical repair was eight days. Scleral show was observed in two patients $(2.6 \%)$ due to scar contracture of the subciliary incision whereas one patient had surgical removal of the PPEI.

Conclusion: The present study revealed that PPEI is a reliable and flexible material for the reconstruction of orbital floor fractures with a low risk of complications. To prevent or minimize postoperative complications, the orbital septum must be repaired meticulously.

Keywords: Orbital fractures, reconstructive surgery, polyethylene, implants, artificial.
Correspondence: Nese Kurt Ozkaya

Department of Plastic Reconstructive Aesthetic Surgery, Sivas Cumhuriyet University Faculty of Medicine, Sivas, Turkey.

E-mail: ozkayanesekurt@gmail.com

Received: 11.4.2020; Accepted: 7.6.2020
Online available at: www.entupdatesjournal.org 


\section{Introduction}

Orbital floor fractures are of great importance because of the contiguity of the orbital floor to critical structures such as the maxillary sinus, orbital neurovascular bundles and ocular structures. Surgical repair is definitely indicated if there is a significant enophthalmos ( $>2 \mathrm{~mm}$ posterior displacement), continued oculocardiac reflex, pinched muscle or periorbital soft tissue restricting eye movement, presence of a large orbital floor defect ( $>25 \%$ of the orbital floor), or presence of symptomatic diplopia continuing seven to 10 days after the trauma. ${ }^{[1-3]}$ Decisions on surgery are varied, with the most critical issues being the surgical approach to be selected and whether to use autologous or alloplastic materials for the reconstruction.

Various approaches, including transcutaneous, transconjunctival and endoscopic transnasal/transmaxillary, have been defined to reach the orbital floor. ${ }^{[4-7]}$ Each approach has its advantages and potential limitations. Furthermore, besides the use of autologous grafts, various allogenic materials have been described for orbital floor reconstruction, such as titanium mesh, silicon, teflon, PPEI, etc. The purpose of the present study was to evaluate patients who had reconstruction of an orbital floor fracture using PPEI and to present clinical and surgical outcomes according to the early, intermediate and late postoperative follow-ups.

\section{Materials and Methods}

The present study included 76 patients with an isolated or complex orbital floor fracture who underwent surgery between July 2000 and July 2018 in the plastic reconstructive and aesthetic surgery department of Cumhuriyet University Hospital. For all patients, a PPEI was used for fracture repair. Local institutional ethics committee approval was obtained (no: 2019-05/46), and all procedures were in accordance with the Declaration of Helsinki and its later amendments. The exclusion criteria were as follows: (1) patients whose clinical data were not available from the hospital database, (2) patients who did not accept surgical treatment, (3) patients in which orbital floor stabilization was achieved without the use of any alloplastic or autogenic material, and (4) patients who declined a request for a phone-call or a clinical visit in the postoperative period. For all patients, the postoperative period was divided into three periods as follows: (1) early period; end of the $1^{\text {st }}$ postoperative month, (2) intermediate period; end of the $6^{\text {th }}$ postoperative month, (3) late period; end of the post- operative $1^{\text {st }}$ year. Demographic and clinical data of the patients, including age, gender, etiology, characteristics of the fracture and the time between the injury and the surgery were recorded. Furthermore, pain, eye movements, diplopia, cosmetic appearance and infraorbital sensory disturbances were examined.

Although the patients were operated on by different surgeons of the same department, the surgical procedures and the treatment approach were almost the same for all patients. Except for two patients in which there was a traumatic laceration of the lower eyelid, a subciliary approach was mainly used, and PPEI (Medpor Surgical Implant, Porex Surgical Inc., College Park, Georgia, USA) was the preferred alloplastic material in all patients. Following insertion of a PPEI to the orbital floor, orbital septum repair was performed meticulously using absorbable suture material in all patients.

SPSS software version 22.0 (SPSS Inc., Chicago, IL, USA) was used to evaluate the statistical analysis of all data. Statistically, $\mathrm{p}<0.05$ was accepted as a significant value. Descriptive statistics of the data were calculated in terms of the number and percentage of categorical variables. Median (minimum-maximum) and standard deviation values were used for continuous variables.

\section{Results}

Of the patients, 12 were female and 64 were male with a mean age of $35.17 \pm 14.35$ years. Fifty-seven patients $(75 \%)$ were between the ages of 21-49 years. The most common cause of injury was in-vehicle traffic accidents $(n=31$, $40.8 \%$ ), followed by falls ( $\mathrm{n}=19,25 \%$ ), physical assaults $(\mathrm{n}=17,22.4 \%)$ and pedestrian accidents $(\mathrm{n}=9,11.8 \%)$, respectively. While five patients $(6.6 \%)$ had an isolated orbital floor fracture, 71 (93.4\%) had a concomitant fracture of other facial bones. The mean time between the injury and the surgery was $8 \pm 1.93$ days (range, $5-18$ days). There was no pain, limited eye movements, deformity, diplopia or enophthalmos in the early period. However, there was edema in all patients, palpebral asymmetry in five patients $(6.6 \%)$ and infraorbital sensory disturbances in 59 patients (77.6\%). In the intermediate period, two patients $(2.6 \%)$ had a scleral show, five $(6.6 \%)$ had sensory disturbances and one $(1.3 \%)$ had cold intolerance in the infraorbital region.

Forty-seven patients $(61.8 \%)$ were able to be reached by a phone call or a clinical visit for evaluating the outcomes of the late period. There was a scleral show in 2 
patients $(2.6 \%)$ in this period due to scar contracture of the subciliary incision. Of the patients, only one had undergone surgery for removal of the PPEI due to recurrent skin edema and purulent discharge in the medial lower eyelid (Figure 2). During the surgery, it was macroscopically noted that there was preseptal inflammation due to chronic dacryocystitis, but there was no sign of postseptal infection and no contamination or infection of the PPEI. The implant was removed and sent for microbiologic examination. The culture was recorded as negative and the patient was treated with antibiotherapy directed to dacryocystitis.

\section{Discussion}

In the present study, study most of the patients with an orbital floor fracture in which reconstruction was performed using a PPEI were male, of middle age, and commonly injured due to an in-vehicle traffic accident. Furthermore, most of the patients were admitted at a relatively late period; the mean elapsed time to the surgery was on the 8th day of the trauma. The injury was commonly unilateral, and isolated orbital floor fractures were very few.

It has been reported that the postoperative complication rate of fragmented, displaced or extremely complicated periorbital fractures is low if the surgery is performed within the first 48 hours. $^{[8]}$ It is advocated that early repair aids in ensuring periorbital stability, achieving infection control, increasing the circulation of tissues by decompression and preventing fibrosis and atrophy of the orbital soft tissue. ${ }^{[2,8,9]}$ Although the results of a recent meta-analysis suggest that early repair is beneficial due to a multifactorial improvement, ${ }^{[10]}$ the level of evidence of studies supporting early repair is low. In our study, most of the patients were operated in a relatively late period, however, inconsistent with the literature, ${ }^{[2,8,9]}$ we did not encounter a high rate of complications in the postoperative period.

Subciliary and transconjunctival incisions are the most commonly used approaches to reach the orbital floor. In many studies, subciliary incision-related complications such as scarring, scleral show, ectropion and palpebral asymmetry have been reported. ${ }^{[4,11]}$ Endoscopic-assisted transnasal/transmaxillary approaches have been described to avoid lower lid incision-related complications. Except for two cases, we performed subciliary incision for all other patients, and only two had a scleral show. This rate was much lower than the preexisting literature. ${ }^{[4,9,10]}$ In our opinion, meticulous repair of the orbital septum following insertion of the PPEI to the orbital floor is the main reason for our low rate of scleral show or other lower lid complications.

Bone, cartilaginous and fascial autografts are the most suitable materials for orbital floor reconstruction due to their non-allergenic and non-carcinogenic nature, and also high biocompatibility. ${ }^{[12,13]}$ However, there are disadvantages of using autografts, such as increased duration of surgery, donor site morbidity, difficulties in shaping the graft and unpredictable graft resorption rate. ${ }^{[13,14]}$ Alloplastic implants are consistent synthetic materials. PPEI is one of the most commonly used alloplastic materials for orbital floor reconstruction. It is a widely available, strong and shapeable material. Its porous structure enables vascular and bone ingrowth leading to soft tissue adherence and reduced risk of infection. ${ }^{[15-17]} \mathrm{It}$ is simple to use, has good strength, but it is a bit flexible so it can be shaped by heat application. ${ }^{[1,2,18,19]}$ In the literature, several complications of PPEI use, such as foreign body reaction, hematoma, and enophthalmos, have been described. ${ }^{[20-22]}$ It is a safe material, almost as common as autologous grafts in both acute orbital floor fractures and late complications. Wajih et al. ${ }^{[23]}$ found similar complication rates using bone graft and PPEI. Furthermore, in large calvarial defects or socket reconstruction, exposure has been reported in stretched places that have to be placed immediately under the skin or under the flap. ${ }^{[24,25]}$

In experimental studies, PPEI has been shown to be a prefabricated material that retains its shape in the transferred tissue without displacement. ${ }^{[18,19]}$ In order to prevent the implant from being exposed, if it is prefabricated and two months elapse, as in these experimental studies, the PPEI will be integrated into the flap. Better results can be obtained if reconstruction is performed after integration. The exposure complication of PPEI is common in socket reconstruction in the literature. ${ }^{[26]}$ Fernandes et al. [27] reported that they created a cover to protect the PPEI with the use of alopecic skin in conjunction with a temporoparietal fascia flap in ear reconstruction. Furthermore, in this way, they reduced the risk of implant exposure. In all our cases, orbital septum repair was provided after the PPEI was placed. We think that the other advantage of orbital septum repair is to prevent displacement or exposure of the implant, which was observed in none of our patients. Furthermore, we also believe that anterior coverage of the PPEI with a durable orbital septum reduces the risk 
of infection by acting as a barrier.

The major limitation of our study was evaluating the late postoperative period of the patients via a phone call, which may have resulted in subjective data regarding postoperative complications. However, in our opinion, the length of the study period and the high number of patients may contribute to the literature in terms of using PPEI for orbital floor fractures.

\section{Conclusion}

In summary, the risk of complications is low with a subciliary approach if the periorbital tissues are not excessively damaged and the dissection is performed with great care. PPEI is an alloplastic material that can be used safely with a low complication rate in the reconstruction of orbital floor fractures. It should be kept in mind that the orbital septum should be repaired carefully after orbital floor reconstruction using PPEI. We believe that this maneuver also prevents displacement and infection of the implant.
Ethics Committee Approval: The study protocol was approved by the local ethics committee (no: 2019-05/46).

Informed Consent: Informed consent was obtained from all individual participants included in the study.

Author Contributions: Designing the study N.K.O., A.R.E.; Collecting the data - N.K.O.; Analysing the data - N.K.O., A.R.E.; Writing the manuscript N.K.O., A.R.E.; Confirming the accuracy of the data and the analyses - N.K.O., A.R.E.

Conflict of Interest: The authors have no conflicts of interest to declare.

Financial Disclosure: The authors declare that the present study has received no financial support.

\section{Acknowledgments: None}

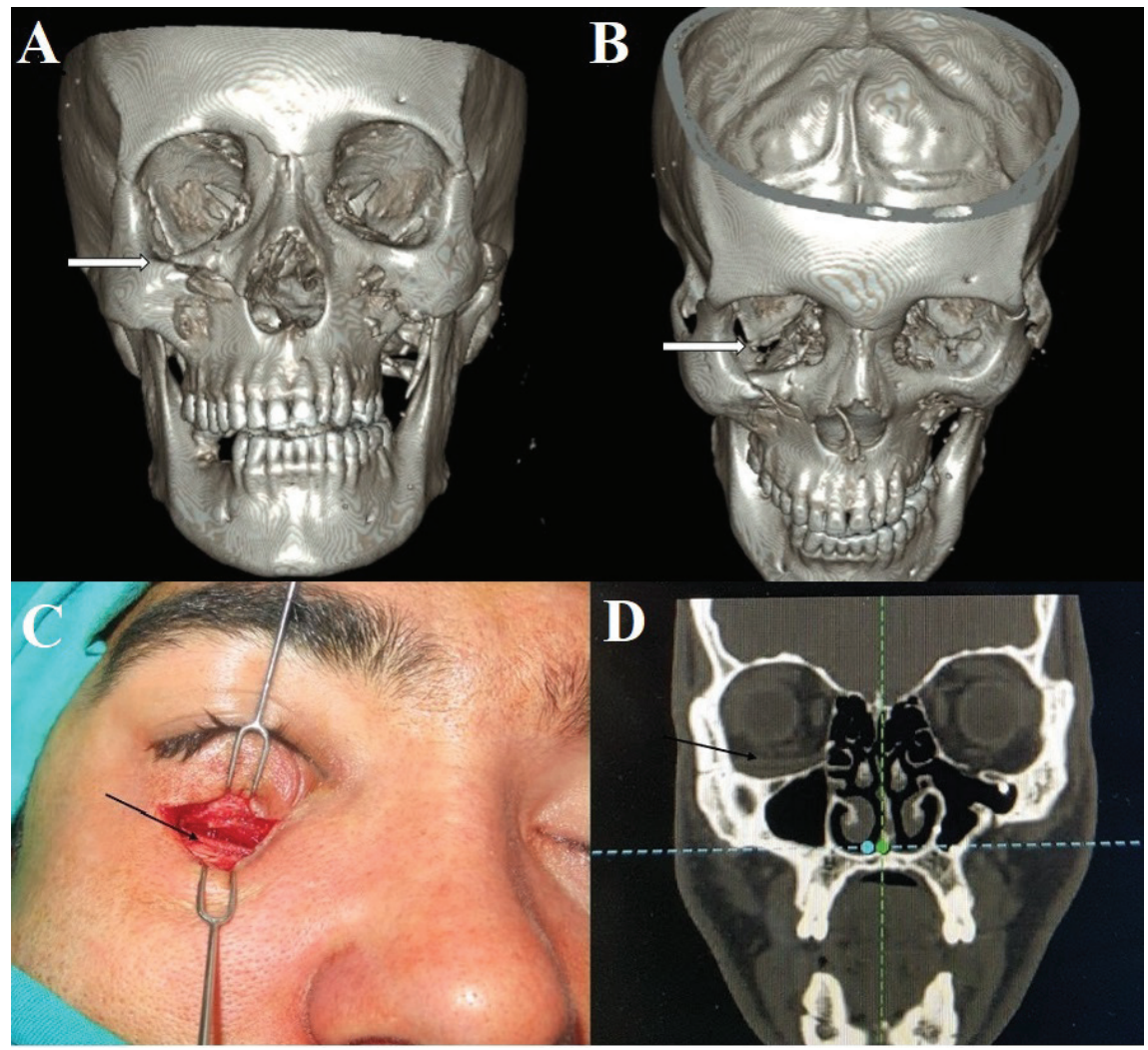

Figure 1. A-B. Three-dimensional tomographic images of the patient with a right orbital floor fracture. White arrows indicate fracture lines.C. Intraoperative image of the right orbital floor fracture reconstruction using a PPEI. D. Postoperative coronal CT image of the patient. (Black arrows show the PPEI in figure $\mathrm{C}$ and D) 


\section{References}

1. Ellis E 3rd, el-Attar A, Moos KF. An analysis of 2,067 cases of zygomatico-orbital fracture. J Oral Maxillofac Surg 1985;43:417-28.

2. Burnstine MA. Clinical recommendations for repair of isolated orbital floor fractures: an evidence-based analysis. Ophthalmology 2002;109:1207-10.

3. Hsu CK, Hsieh MW, Chang HC, Tai MC, Chien KH. Anatomic Factors Predicting Postoperative Strabismus in Orbital Wall Fracture Repair. Sci Rep 2019;9:14785.

4. Al-Moraissi EA, Thaller SR, Ellis E. Subciliary vs. transconjunctival approach for the management of orbital floor and periorbital fractures: a systematic review and meta-analysis.J Craniomaxillofac Surg 2017;45:1647-54

5. Pedemonte C, Muñoz T, Valenzuela K, Díaz M, González LE, Vargas I. Reconstruction of medial orbital wall using a retrocaruncular approach. J Craniomaxillofac Surg 2018;46:1726-30.

6. Pagnoni M, Giovannetti F, Amodeo G, Priore P, Iannetti G. Endoscopic endonasal versus transfacial approach for blowout fractures of the medial orbital wall. J Craniofac Surg 2015;26:247-9.

7. Soejima K, Shimoda K, Kashimura T, et al. Endoscopic transmaxillary repair of orbital floor fractures: a minimally invasive treatment. J Plast Surg Hand Surg 2013;47:368-73.

8. Wu PS, Matoo R, Sun H, Song LY, Kikkawa DO, Lu W. Single-stage soft tissue reconstruction and orbital fracture repair for complex facial injuries. J Plast Reconstr Aesthet Surg 2017;70:1-6.

9. Al-Moraissi E, Elsharkawy A, Al-Tairi N, et al. What surgical approach has the lowest risk of the lower lid complications in the treatment of orbital floor and periorbital fractures? A frequentist network meta-analysis. J Craniomaxillofac Surg 2018;46:2164-75.

10. Jazayeri HE, Khavanin N, Yu JW, et al. Does Early Repair of Orbital Fractures Result in Superior Patient Outcomes? A Systematic Review and Meta-Analysis. J Oral Maxillofac Surg 2020;78:568-77.

11. Neovius E, Clarliden S, Farnebo F, Lundgren TK. Lower Eyelid Complications in Facial Fracture Surgery. J Craniofac Surg 2017;28:391-3.

12. Kronig SA, van der Mooren RJ, Strabbing EM, et al. Pure orbital blowout fractures reconstructed with autogenous bone grafts: functional and aesthetic outcomes. Int J Oral Maxillofac Surg 2016;45:507-12.

13. Sakakibara S, Hashikawa K, Terashi H, Tahara S. Reconstruction of the orbital floor with sheets of autogenous iliac cancellous bone. J Oral Maxillofac Surg 2009;67:957-61.

14. Polacco MA, Kahng PW, Sudoko CK, Gosselin BJ. Orbital Floor Reconstruction: a Comparison of Outcomes between Absorbable and Perma- nent Implant Systems. Craniomaxillofac Trauma Reconstr. 2019;12:193-

15. Ozturk S, Sengezer M, Isik S, Turegun M, Deveci M, Cil Y. Long-term outcomes of ultra-thin porous polyethylene implants used for reconstruction of orbital floor defects. J Craniofac Surg 2005;16:973-7.

16. Lin IC, Liao SL, Lin LL. Porous polyethylene implants in orbital floor reconstruction. J Formos Med Assoc 2007;106:51-7.

17. Hunter D, Baker S, Sobol SM. Split calvarial grafts in maxillofacial reconstruction. Otolaryngol Head Neck Surg 1990;102:345-50.

18. Can Z, Erçöçen AR, Apaydin I, Demirseren E, Sabuncuoğlu B, Yormuk E. Tissue engineering of high density porous polyethylene implant for three-dimensional reconstruction: an experimental study. Scand J Plast Reconstr Surg Hand Surg 2000;34:9-14.

19. Can Z, Apaydin I, Erçöçen AR, Demirseren ME, Sabuncuoğlu B. Prefabrication of a high-density porous polyethylene implant using a vascular induction technique. Ann Plast Surg 1998;41:264-9.

20. Timoney PJ, Clark JD, Frederick PA, et al. Foreign Body Granuloma Following Orbital Reconstruction with Porous Polyethylene. Ophthalmic Plast Reconstr Surg 2016;32:137-8.

21. Aryasit O, Ng DS, Goh ASC, Woo KI, Kim YD. Delayed onset porous polyethylene implant-related inflammation after orbital blowout fracture repair: four case reports. BMC Ophthalmol 2016;16:94

22. Slentz DH, Rajjoub L, Domanski M. Atraumatic Delayed Orbital Hematoma Sixteen Years After Orbital Floor Fracture Repair With Porous Polyethylene Implant. J Craniofac Surg 2019;30:539-40.

23. Wajih WA, Shaharuddin B, Razak NH. Hospital Universiti Sains Malaysia experience in orbital floor reconstruction: autogenous graft versus Medpor. J Oral Maxillofac Surg 2011;69:1740-4.

24. Konofaos P, Thompson RH, Wallace RD. Long-Term Outcomes With Porous Polyethylene Implant Reconstruction of Large Craniofacial Defects. Ann Plast Surg 2017;79:467-72.

25. Avashia YJ, Sastry A, Fan KL, Mir HS, Thaller SR. Materials used for reconstruction after orbital floor fracture. J Craniofac Surg 2012;23:19917.

26. Lang P, Kim JW, McGovern K, et al. Porous orbital implant after enucleation in retinoblastoma patients: indications and complications. Orbit 2018;37:438-43.

27. Fernandes JR, Driscoll DN. Burn Ear Reconstruction Using Porous Polyethylene Implants and Tissue Expansion. J Burn Care Res 2016;37:34852.

This is an open access article distributed under the terms of the Creative Commons Attribution-NonCommercial-NoDerivs 3.0 Unported (CC BY- NCND3.0) Licence (http://creativecommons.org/licenses/by-nc-nd/3.0/) which permits unrestricted noncommercial use, distribution, and reproduction in any medium, provided the original work is properly cited.

Please cite this article as: Kurt Ozkaya N, Ercöcen AR. Reconstruction of orbital floor fractures using a porous polyethylene implant: outcomes in the early, intermediate and late postoperative periods. ENT Updates 2020;10(2): 321-325. 